\title{
Searching the Web: Toward Maximizing Relevance
}

\author{
Mark A. Spasser, PhD, MLS, Jewish Hospital College of Nursing and Allied Health, St. Louis, Missouri
}

\section{REPRINT REQUESTS:}

Mark A. Spasser, PhD, MLS

Chief, Library and Information

Services/Associate Professor

Jewish Hospital College of Nursing

and Allied Health

306 S. Kingshighway Blvd.

MS:90-30-625

St. Louis, MO 63110-1091

Telephone: 314-454-8171

Email: mas1200@bjc.org

KEYWORDS:

Internet; Search engines; Queries

RECEIVED:

August 1, 2002

REVISED AND ACCEPTED:

August 13, 2002

\section{Clinical Medicine \& Research}

Volume 1, Number 1: 69 - 70

(2003 Clinical Medicine \& Research

www.mfldclin.edu/clinmedres
Searching for information on the Web is paradoxically easy but frustrating. There is an increasingly vast amount of high-quality information available on the Internet, but finding it can seem like groping through the world's largest haystack for the proverbial needle. This review discusses some of the most basic and important methods and techniques, (table 1) applicable to almost any search using almost any search engine, whose thoughtful application ensures that the information found is both high-quality and relevant.

\section{TYPES OF SEARCH ENGINES}

Centralized - Google, Teoma, and AlltheWeb Specialized/expert - Pubmed (Medline), AllLaw, MedHunt

Meta search engines - Meta engines are becoming less important due to centralized search engines indexing the Web so comprehensively, and as a result will not be covered in this review

\section{GUIDING PRINCIPLES}

Be specific: Centralized search engines, such as Google and AlltheWeb, work better when you use multiple keywords that are unlikely to pop up on irrelevant pages. Also, of course, use specialized search engines whenever possible.

Evaluate retrieval: Listing length of candidate documents returned by queries submitted to search engines is directly related to amount of evaluation time needed.

Gauge time: Whereas actual search time in getting candidate listings from search engines is relatively fast, document-by-document download and review is the time consuming part of the process.

Read instructions: Analogous to database interfaces, every search engine has its own syntactical peculiarities; entering a query properly can mean the difference between finding what you're after and being deluged by irrelevant links.

Go Boolean: Most sites permit the construction of queries using the AND, OR, and NOT Boolean operators (use parentheses if you use more than one Boolean term). Also the + and - implicit operators, are almost universally supported.

Be exacting: Surround words with quotation marks to search them as a phrase. The utility of this widely supported search feature to ferret out only the most relevant information can't be overstated.

Get advanced: Many engines come with an advanced search page offering additional query types and sorting options, which are especially helpful when a simple search bombards you with pages of links.

Be steadfast: If the first site is not successful, try another; bookmark several and try new contenders from time to time. Each engine has potentially complementary strengths and limitations.

Save pages: Once documents are located, keep track of them; at the very least bookmark them. 
Table 1. Useful search features common to most search engines.

\begin{tabular}{lll}
\hline Search Feature & Example & Rule \\
\hline $\begin{array}{ll}\text { Implied Boolean Operators } \\
+\end{array}$ & +bipolar +depression & $\begin{array}{l}\text { The + symbol instructs the search engine to } \\
\text { return only pages that include that word (or } \\
\text { words). }\end{array}$ \\
- & +bipolar +depression & $\begin{array}{l}\text { The - symbol instructs the search engine to } \\
\text { return only pages that exclude that word (or } \\
\text { words). }\end{array}$
\end{tabular}

Power of Boolean Searches

AND

OR

NOT/AND

Double Quotes:

Phrase searching

Truncation/Wildcards:

Special Characters are Useful

$$
\text { *, ?, \# }
$$

Case Sensitivity:

Specify Document Type

Utilize Expertise bipolar AND depression

(bipolar OR manic) AND depression

bipolar AND depression AND NOT psychotic

(bipolar AND depression) AND NOT psychotic

"bipolar depression"

"bipolar depression" OR "manic depression" AND NOT psycho* (searches for both psychosis or psychotic)
AND indicates that only those web pages having all words in them will be retrieved (narrows search).

OR indicates that web pages having any term will be retrieved (broadens search).

OR is the operator used to construct searches using synonyms.

NOT/AND indicates that web pages having the term or terms will not be retrieved (narrows search).

Multiple ANDs, ORs, AND NOTs can be used in the same search statement; must use parentheses.

Phrase searching instructs the search engine to return only pages where the terms appear in the exact order specified.

Instruct the search engine to return multiple forms of a term and/or words that have most of the term in common, except for a letter or two.

Use thoughtfully. In this case, not only will psychosis and psychotic be found, but so will psychological, etc.

Most search engines treat lower case searches as universal, but will perform a case sensitive search if any letter is capitalized. For example, search for the term web, the engine will return pages containing web or Web. Search for Web, only pages containing Web will be returned.

To continue building on the examples used above, a search for clinical trials of medications used to treat manic-depressive illness, use the phrase "clinical trial" in the search: Ex., ("manic depressive illness" OR "bipolar depression" OR "manic depression") AND "clinical trials." Using trial* returns pages that mention either trial or trials.

If the purview of a particular query falls within the scope of a specialized search engine, use it. For example, if the goal of a search is images of medical instruments, then by all means, use a image search engine, such as Ditto. In addition, some centralized engines, such as Google, allow the search to be limited to images (Google Image Search). If, for example, the question involves federal law, than AllLaw is the place to go.

\section{CONCLUSION}

Search engines mentioned in the review:

Google: http://www.google.com

AlltheWeb: http://www.alltheweb.com

Time is well-spent in learning to pose a proper query and to

Teoma: http://www.teoma.com

Ditto: http://www.ditto.com

AllLaw: http://www.alllaw.com

MedHunt: http://www.hon.ch/MedHunt 